\title{
0348 UNDERSTANDING HOW WE CAN ENGAGE AND MAINTAIN OLDER ADULTS IN EXERCISE CLASSES: THE ROLE OF THE EXERCISE INSTRUCTOR
}

H Hawley, D Skelton, C Todd* Correspondence: The School of Nursing, Midwifery and Social Work, The University of Manchester, University Place, Oxford Road, Manchester M13 9PL, UK

\subsection{6/ip.2010.029215.348}

Specific targeted exercise is an important part of the falls care pathway. It is a key factor in primary fall prevention; it enables older people to regain mobility following a fall and can prevent further falls. However, engaging older adults in physical activity is difficult. Those who have been through falls rehabilitation do not maintain their exercises and revert to prerehabilitation state (Hawley, 2009). This is the first part of a larger study looking at older adults uptake and adherence to exercise classes and develops the work of Yardley et al (2006a, 2006b, 2007) who showed that older adults are more likely to engage in exercise if they have higher coping appraisal (enjoyment of the session, improvement in well-being. This study will explore how instructors attitudes relate to their participants attitudes and whether there is any impact on their coping appraisal. The first phase aims to establish a broad picture of exercise sessions delivered to older adults across UK. It examines characteristics and attitudes of instructors. Using the mailing lists of three training providers we surveyed some 2000 instructors across the UK who are qualified to deliver exercise to older 
adults, who are delivering in a variety of settings, establishing a broad picture of instructors and their classes. We asked questions about the sort of exercise provided and characteristics of the classes. We investigated attitudes using a modified AFRIS. We have 731 responses and these are currently being analysed. Findings will be discussed and an outline of phase 2 of the study provided.

\section{References}

Hawley H. Older Adults' Perspectives on home exercise after falls rehabilitation an exploratory study. Health Education Journal. 2009;68,207-18. doi:

10.1177/0017896909339533.

Yardley L, Bishop F, Beyer N, Hauer K, Kempen Gl, Piot-Ziegler C, Todd C, Cuttelod T, Horne M, Lanta K and Holt AR. Older people's views of falls-prevention interventions in six European countries. The Gerontologist 2006; 46:650-60.

Yardley L. Donovan-Hall M, Francis K and Todd C. Older People's views of advice about falls prevention: a qualitative study. Health Education Research 2006;21:508-17.

Yardley L, Donovan-Hall M, Francis C and Todd C. Attitudes and beliefs that predict

older people's intention to undertake strength and balance training. Journal of

Gerontology: Psychological Sciences 2007;2:199-225. 